tumours. ${ }^{11}$ Embolisation of the spleen has had a less happy history. Treatment of the whole spleen for enlargement may produce pain, abscess formation, septicaemia, and even splenic rupture; partial embolisation may be as effective a treatment with a lower morbidity. ${ }^{10}$

Gastrointestinal bleeding in patients who are not fit for surgery is a common and unsolved problem for which embolisation may offer help. Reuter has reported 40 successful embolisations to control such haemorrhage. ${ }^{12}$ Bleeding from gastro-oesophageal varices complicating portal hypertension has also been successfully attacked, with access to the portal circulation by a percutaneous transhepatic route. ${ }^{10}$ Nevertheless, the risks and effectiveness of this technically impressive manoeuvre must be weighed against the less invasive technique of injection of the varices through the oesophagoscope.

Angiomas, particularly those containing arteriovenous fistulae, provide another example of a surgical problem for which embolisation has shown benefits, either as the definitive treatment or as a preliminary manoeuvre to convert a difficult or impossible operation into a straightforward one. ${ }^{13}$ Particular success has been achieved in nasal angiofibromas. ${ }^{14}$ Among other clinical conditions for which embolisation has been tried and found helpful are epistaxes, ${ }^{15}$ haemoptysis, ${ }^{16}$ aneurysms, ${ }^{17}$ postpartum haemor: ${ }^{-h}$ age, ${ }^{18}$ and haemorrhage after pelvic fractures. ${ }^{19}$

The technique is still in an early stage of development, yet surprisingly few complications have been reported. Symptoms due to ischaemia or infarction of the treated organ are to be expected. Strokes may result either from overflow of emboli into the cerebral circulation or from failure to predict the anatomy and haemodynamics of head and neck angiomas and arteriovenous fistulae, and are particularly distressing complications. ${ }^{20}$ Nevertheless, fortunately in the hands of experts they are rare. Most other complications are due to specific problems of technique and may be expected to be less common as experience grows. However great that experience becomes, the technique will, nevertheless, remain complex and potentially dangerous. The technical pitfalls and the place of embolisation compared with alternative forms of treatment must, therefore, be very carefully defined before it becomes a skill embraced by every major radiology department. Furthermore, embolisation procedures should be regarded as akin to operations, needing full preoperative and postoperative care and close co-operation between radiologist and clinician.

A E Young

Consultant Surgeon,

St Thomas's Hospital,

London SE1 7EH

${ }^{1}$ Dawbarn RHM. The starvation operation for malignancy in the external carotid area. Its failures and successes. $7 A M A 1904 ; 43: 792-5$.

2 Kunstlinger F, Brunelle F, Chaumont P, Doyon D. Vascular occlusive agents. AfR $1981 ; \mathbf{1 3 6}: 151-6$.

${ }^{3}$ Goldstein HM, Medellin H, Beydoun MT, et al. Transcatheter embolisation of renal cell carcinoma. $A \mathcal{F} R$ 1975;123:557-62.

4 Danis RK, Wolverson MK, Graviss ER, O'Connor DM, Joyce PF, Craddock TV. Peroperative embolisation of Wilms' tumors. Am $\mathcal{F} D$ is Child 1979;133:503-6.

Muller JH, Engel D, Waigand J, Mebel M. Late results following palliative vascular embolisation in inoperable kidney tumours. $Z$ Urol Nephrol 1978;71:481-93.

${ }^{6}$ Curet P, Roche A, Riche MC, Merland JJ, Doyon D. Therapeutic embolisation for traumatic renal haemorrhage. Nouv Presse Med 1980; 9:2633-6.

' Seybold P, Lux E, Grosse Verhold R, Zeitler E, Gessler V. Embolisation of renal arteries: an alternative to nephrectomy in the treatment of patients with dialysis and malignant hypertension. Klin Wochenschr $1980 ; 58: 696-700$.

${ }^{8}$ Carmignani G, Belgrano E, Puppo P, Cichero A, Giuliano L. Transcatheter embolisation of the hypogastric arteries in cases of bladder hemorrhage from advanced pelvic cancers: followup in 9 cases. 7 Urol $1980 ; 124$ : 196-220.

${ }^{9}$ Wafula JMC, Davies P. Treatment of spontaneous priapism by embolisation of internal pudendal artery. Br Med F $1981 ; 282: 363-4$.

1" Pereiras R, Schiff E, Barkin J, Hutson D. The role of interventional radiology in diseases of the hepatobiliary system and the pancreas. Radiol Clin North Am 1979;17:555-605.

${ }^{11}$ Allison DJ. Therapeutic embolisation. Br f Hosp Med 1978;20:707-15.

${ }^{12}$ Reuter SR. Embolisation of gastrointestinal hemorrhage. $A \mathcal{F R} 1979 ; 133$ : 557-8.

${ }^{13}$ Kaufman SL, Kumar AAJ, Roland J-MA, et al. Transcatheter embolisation in the management of congenital arteriovenous malformations. Radiology 1980;137:21-9.

${ }^{11}$ Lasjaunias P, Picard L, Manelfe C, Moret J, Doyon D. Angiofibroma of the nasopharynx. $\mathcal{F}$ Neuroradiol $1980 ; 7: 73-95$.

${ }^{15}$ Merland JJ, Melki JP, Chiras J, Riche MC, Hadjean E. Place of embolisation in the treatment of severe epistaxis. Laryngoscope 1980;90:1694704.

${ }^{16}$ Rémy J, Arnaud A, Fardou H, Giraud R, Voisin C. Treatment of hemoptysis by embolisation of bronchial arteries. Radiology 1977;122: 33-7.

17 Leather RP, Shah D, Goldman M, Rosenberg M, Karmody AM. Nonresective treatment of abdominal aortic aneurysms. Use of acute thrombosis and axillofemoral bypass. Arch Surg 1979;114:1402-8.

${ }_{18}$ Pais SO, Glickman M, Schwartz P, Pingould E, Berkkwitz R. Embolisation of pelvic arteries for control of postpartum hemorrhage. Obstet Gynecol 1980;55:754-8.

19 Ring EJ, Athanasoulis C, Waltman AC, Margolies MN, Baum S. Arteriographic management of hemorrhage following pelvic fracture. Radiology 1973;109:65-70.

20 Dubois PJ, Kerber CW, Heinz ER. Interventional techniques in neuroradiology. Radiol Clin North Am 1979;17:515-42.

\section{A new task for human growth hormone?}

Human growth hormone is well established as the treatment for children with growth hormone deficiency. In Britain supplies of the hormone obtained from cadaveric pituitary glands have been such that all children who need it have been able to receive treatment, albeit under carefully controlled conditions. Unfortunately this state is threatened by a fall in the rate of pituitary collection-so that the introduction of biosynthetic human growth hormone, derived from recombinant DNA technology, will not come a moment too soon.

From time to time patients not considered to have growth hormone deficiency by the usual criteria have been said to benefit from treatment with human growth hormone, ${ }^{1}$ but the numbers have been so small as to have little effect on the demand for the hormone. Supply and demand may, however, be seriously thrown out of balance by a whole new prospect for treatment. In a recent issue of the New England Fournal of Medicine Rudman et $a l^{2}$ have argued that an unrecognised group of short children can benefit from human growth hormone, with a prevalence greatly exceeding that of true growth hormone deficiency, which is about 1 child in $5000 .^{3}$ This proposal has implications for the supply of human growth hormone so profound that the findings of Rudman et al require very careful consideration.

Their paper is the fifth in a series published by the Emory group since 1978, originating in a search for a quick and economical method of assessing the long-term response of a patient to human growth hormone. ${ }^{45}$ Using the techniques as developed in patients with conventional growth hormone deficiency they continued to study a group of short children with what they called normal variant short stature, a term borrowed from the late David Smith. ${ }^{6}$ These they define as having the following characteristics: a current height and predicted adult height below the 3rd centile; a birthweight greater than $2.5 \mathrm{~kg}$; no apparent cause for the short stature, 
and a peak serum radioimmunoassayable concentration of growth hormone above $24 \mathrm{mIU} / 1$ in provocation tests.

In 1979 they subgrouped the children with normal variant short stature into four categories on the basis of their metabolic and short-term response to growth hormone. ${ }^{7}$ Groups one and two did not respond, while groups three and four showed responses similar to those seen in growth-hormone deficient children. The next year they reported further observations ${ }^{8}$ showing that these groups three and four consisted of children who produced a growth hormone apparently normal by immunoassay criteria but of low activity in a radioreceptor assay. Serum concentrations of somatomedin-C, measured by immunoassay, were also low. They proposed that in these children the growth hormone molecule was of an abnormal structure with low biological activity producing physiological consequences comparable with true growth hormone deficiency but normal results on conventional immunoassays. The latest paper ${ }^{2}$ shows the result of treating 20 children with normal variant short stature from the four groups and five with true growth hormone deficiency with daily human growth hormone over six months. The children in normal variant short stature groups three and four responded in a manner indistinguishable from the children with true growth hormone deficiency. In contrast, those in normal variant short stature groups one and two showed no response to long-term treatment with human growth hormone, in keeping with the earlier observations in metabolic and short-term growth-response tests. The implications of these findings are that children in groups three and four should be treated long-term with human growth hormone; as Rudman and his co-workers consider their numbers to be much greater than the numbers with true growth hormone deficiency the implications for supply of human growth hormone are clear.

We should look at the results from the Emory group in three ways. Firstly, do they stand up to critical examination on methodological grounds? In some of the earlier papers, where they were reporting measurable changes in growth velocity after only 10 days of growth-hormone replacement, there might very well have been some reason for doubts. Nevertheless, the published results and their analysis looked indisputable, and with the more recent observations concerning growth changes measured over six months of treatment the results must be taken at face value.

Having accepted the results, we must now try to interpret them. What type of patient has Rudman's group been seeing ? The growth velocities in the six months before treatment with growth hormone averaged $1.7 \mathrm{~cm} / \mathrm{yr}$, in both the patients with growth hormone deficiency and with normal variant short stature. ${ }^{2}$ This is a remarkably low velocity, even for patients with conventional deficiency of growth hormone, and must imply considerable selection of patients. Given that these patients have been growing at a similar rate for some years, which would be expected in anything other than a recently acquired condition, then heights at entry into the study, three years earlier at the age of 6 , would all have been near the 25 th centile. This would indeed be a strange growth curve for any form of growth hormone deficiency with such a sudden change in growth at that age. Patients with normal variant short stature groups three and four are said by Rudman et al to have an abnormal growth hormone molecule, which would imply onset of the disorder at birth. It is hard to reconcile this hypothesis with the growth curve just described.

There is a second strange feature of the children with normal variant short stature. An earlier paper $^{7}$ gave individual details of the patients' weights and heights. The normal children had weight-for-height ratios $998 \pm 3 \%$ of that expected, if one grossly obese child (their patient 9) is excluded. As usual the children with growth hormone deficiency had a high weight-for-height at $109 \pm 3 \%$ of expected, as did those in normal variant short stature groups three and four. Nevertheless, children in groups one and two had weight-for-heights which were $81 \pm 2 \%$ of expected, only just above the conventional limits considered as indicating wasting. In fact, seven out of 19 of their patients $(37 \%$ in groups 1 and 2$)$ could be categorised as showing severe wasting. We need to know more about these children and whether they are suffering from malnutrition or from some form of deprivation.

Finally we should turn to the epidemiological aspects. Rudman et al acknowledged that considerable selection has taken place in the definition of the study sample and that prevalence estimates are worth very little. They suggest, however, that normal variant short stature accounts for $40 \%$ of short children. They provide no justification for this statement, and, taking their definition of normal variant short stature, most authorities would place the figure much lower. Taken at face value, their estimate of $32 \%$ of patients with normal variant short stature being in groups three and four ${ }^{7}$ would suggest that some $15 \%$ of all short children, that is those below the 3rd centile, suffer from this apparently treatable condition. This would give a prevalence of 1 in 250 children in the general population. A tenth of this number would seem more realistic and would still give us a frequency twice that of conventional growth hormone deficiency.

Whatever we make of Rudman's figures and the extrapolations that can be made from them, further study is surely needed. The latest paper ${ }^{2}$ clearly shows ways of defining those children who could respond to human growth hormone and yet have apparently normal immunoassayable growth hormone responses to suitable provocation. Measurements of radioreceptor assayable growth hormone and the short-term responses of somatomedin- $\mathrm{C}$ to injections of growth hormone could provide quick and sensible answers to this problem.Such a study in a random sample of short children should give us a clear idea of the prevalence of the disorder in the community and should be undertaken without delay.

\section{A PREece}

Senior lecturer in growth and development,

Institute of Child Health,

University of London, and

Honorary consultant physician,

Hospital for Sick Children,

London WC1N $1 \mathrm{EH}$

Trygstad $\mathrm{O}$. Transitory growth hormone deficiency successfully treated with human growth hormone. Acta Endocrinol (Copenh) 1977;84:11-22.

${ }^{2}$ Rudman D, Kutner MH, Blackston RD, Cushman RA, Bain RP, Patterson JH. Children with normal-variant short stature: treatment with human growth hormone for six months. N Engl f Med 1981 ;305: 123-31.

${ }^{3}$ Vimpani GV, Vimpani AF, Lidgard GP, Cameron EHD, Farquhar JW. Prevalence of severe growth hormone deficiency. $\mathrm{Br} \mathrm{Med} \mathcal{F} 1977$;ii: 427-30.

4 Rudman D, Kutner MH, Fleming GA, et al. Effect of 10-day courses of human growth hormone on height of short children. 7 Clin Endocrinol Metab $1978 ; 46: 28-35$

${ }^{5}$ Rudman D, Kutner MH, Goldsmith MA, Blackston RD. Predicting the response of growth hormone-deficient children to long term treatment with human growth hormone. F Clin Endocrinol Metab 1979;48:472-7.

${ }^{6}$ Smith DW. Growth and its disorders. Philadelphia: W B Saunders Company, 1977.

7 Rudman D, Kutner MH, Blackston RD, Jansen RD, Patterson JH. Normal variant short stature: subclassification based on responses to exogenous human growth hormone. $\mathcal{F}$ Clin Endocrinol Metab 1979;49: 92-9.

${ }^{8}$ Rudman D, Kutner MA, Goldsmith MA, Kenny I, Jennings H, Bain RP. Further observations on four subgroups of normal variant short stature. f Clin Endocrinol Metab 1980;51:1378-84.

${ }^{9}$ Cole TJ. A method of assessing age-standardized weight-for-height in children seen cross-sectionally. Ann Hum Biol 1979;6:249-68. 